EESTI NSV TEADUSTE AKADEEMIA TOIMETISED 26, KOIDE KEEMIA * GEOLOOGIA 1977, Nr. 4

ИЗВЕСТИЯ АКАДЕМИИ НАУК ЭСТОНСКОИ ССР. ТОМ 26 ХИМИЯ * ГЕОЛОГИЯ. 1977, № 4

\title{
ИММОБИЛИЗАЦИЯ ХИМОТРИПСИНА И БЕНЗИЛПЕНИЦИЛЛИНАМИДАЗЫ НА ПОРИСТОМ КРЕМНЕЗЕМЕ С ПОМОЩЬЮ ДИАЗИДА АдиПиновОЙ КИСЛОТЫ
}

V. FEDOSSEJEV, M. MANDEL, A. KOSTNER. KOMOTROPSIINI JA PENITSILLIINAMIDAASI IMMOBILISEERIMINE ADIPIINHAPPEDIASIIDI ABIL KROMOSORB $P$ PINNALE

V. FEDOSEYEV, M. MANDEL, A. KOSTNER. IMMOBILIZATION OF CHYMOTRYPSIN AND PENICILLINAMIDASE ON CHROMOSORB $P$ WITH THE HELP OF ADIPIC ACID DIAZIDE

В настоящее время для ковалентной иммобилизации ферментов используется исключительно большое число самых различных носителей и сшивающих бифункциональных реагентов $\left[{ }^{1-3}\right]$. Несмотря на значительную изученность данного вопроса, нами был найден, синтезирован и использован для иммобилизации химотрипсина (XT) и бензилпенициллинамидазы (БПА) ранее не применявшийся для этой цели бифункциональный реагент - диазид адипиновой кислоты (ДАК). Выбор данного реагента обусловлен простотой его синтеза и тем, что производится он из легко доступного отечественного препарата диметилового эфира адипиновой кислоты. Используемый в качестве бифункционального сшивающего реагента ДАК участвует в реакциях связывания фактически как гексаметилдиизоцианат. В качестве одного из носителей служил ранее никем не испытанный крупнопористый диатомит хромосорб $P$. Пористые диатомиты - дешевый и доступный материал и по содержанию окиси кремния близки к обыкновенному стеклу, т. е. содержат примерно $90 \% \mathrm{SiO}_{2}$.

\section{Экспериментальная часть}

Использованные реакти вы и препараты. Хромосорб $P-$ препарат фирмы «John Manville» (США) (размер частиц 100-120 меш., диаметр пор $1000-10000 A$, удельная поверхность $-1 \mathrm{M}^{2} / 2$, химический состав - $90 \% \mathrm{SiO}_{2}, 4 \% \mathrm{Al}_{2} \mathrm{O}_{3}, 1,5 \% \mathrm{Fe}_{2} \mathrm{O}_{3}, 0,62 \% \mathrm{TiO}_{2}, 0,5 \% \mathrm{CaO}$, $0,5 \% \quad \mathrm{MgO})$.

$\boldsymbol{\alpha}$-химотрипсин - кристаллический препарат фирмы «Реанал» (Венгрия) активностью по АТЭЭ $240 \mathrm{E} /$ ме.

БПА - раствор ферментного препарата из $E$. coli в $0,1 M$ фосфатном буфере $(\mathrm{pH} 7,5)$ производства Рижского завода медицинских препаратов активностью $9000 E / \mu \Omega$ и с содержанием белка 250 мг/мл.

Этиловый эфир $\alpha$-N-ацетил-L-тирозина (АТЭЭ) - препарат фирмы «Реанал» (Венгрия).

Калиевая соль бензилпенициллина (БП) - производство Саранского завода медицинских препаратов. 
Гидразингидрат - реактив Московского химического завода им. П. Л. Войкова.

Диметиловый эфир адипиновой кислоты - реактив Харьковского завода химических реактивов.

$\gamma$-аминопропилтриэтоксисилан - препарат АГМ-9.

Все реактивы использовались без дополнительной очистки.

Активность ферментов определялась рН-статически при 25 (в случае ХТ) и $40^{\circ} \mathrm{C}$ (в случае БПА). Измерения производились путем введения проб свободного или связанного ферментов в реакционный сосуд, содержащий в случае XТ 15 мл 0,01 M АТЭЭ в 0,02 M трис/HCl-буфере (pH 8,0) с растворенными в нем $0,2 \mathrm{M} \mathrm{KCl} \mathrm{и} 0,01 \mathrm{M} \mathrm{AТЭЭ} \mathrm{и} \mathrm{в} \mathrm{случае}$ БПА 10 мл 1,7 $\times 10^{-2} M$ БП (pH 7,5). Ферментативная активность определялась по начальной скорости гидролиза АТЭЭ или БП, измеряемой как расход за минуту (час) $\mathrm{NaOH}$, используемой для нейтрализации АТЭЭ или фенилуксусной кислоты, выделяющихся в ходе гидролиза.

С интез ДАК проводили по методике аналогичной $\left[{ }^{4}\right]$, используемой для синтеза азида фенилуксусной кислоты из ее этилового эфира. Чистый ДАК - маслянистая жидкость, затвердевающая при $0^{\circ}$ и взрывающаяся при трении или нагревании ее растворов [5].

$\mathrm{C}$ иланизация хромосорба проводилась по методике [ $\left.{ }^{6}\right]$.

Св языв ание ферментов с носителем. Перед связыванием ферментов с носителем последний активируют бифункциональным реагентом, для чего хромосорб $P$, активированный $\gamma$-аминопропилтриэтоксисиланом, вносят в эфирный раствор ДАК и оставляют в нем на 10-12 ч при комнатной температуре и постоянном перемешивании. Затем носитель отделяют от раствора, промывают этиловым эфиром и осушают под вакуумом. Связывание ХT с носителем осуществлялось внесением навески активированного хромосорба в раствор фермента в 0,10 M фосфатном буфере (pH 7,1), причем соблюдались следующие соотношения: 2 мл буфера и 10 мг фермента на 1 г носителя. В случае БПА на 1 г хромосорба бралось $10 \mathrm{M}$ раствора фермента в $0,1 \mathrm{M}$ фосфатном буфере активностью $9000 \mathrm{E} / \mathrm{M}$. Взвесь носителя в ферментном растворе оставляют в холодильнике $\left(4-6^{\circ}\right)$ при постоянном перемешивании на 24 ч, после чего носитель отделяют от раствора, промывают сперва буферным раствором ( $\mathrm{pH} 5,0-6,5)$, затем $1 M$ раствором $\mathrm{NaCl}$ в $0,001 M \mathrm{HCl}$ и, наконец, $0,001 \mathrm{M} \mathrm{HCl}$ в случае ХT и водой в случае БПА. Препараты хранятся во влажном состоянии в герметичном сосуде при температуре $4-6^{\circ}$.

\section{Результаты и обсуждение}

Ковалентно связанные на хромосорбе $P$ (активность $100 E$ и $960 E$ на 1 г влажного препарата) ХТ и БПА характеризуются наличием 12-членного связывающего мостика, строение которого показано ниже.

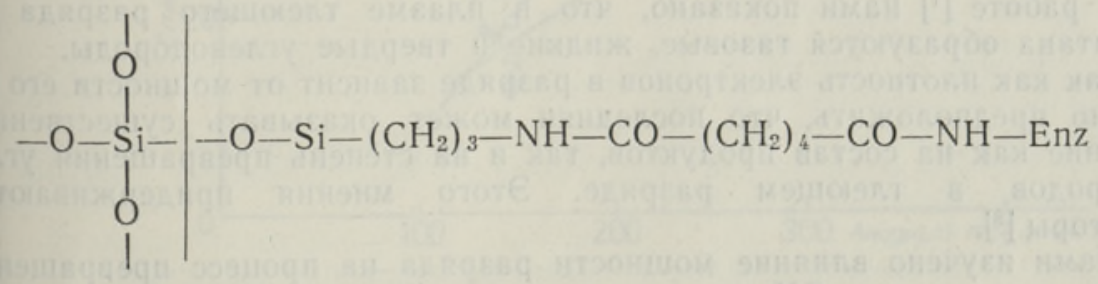

Вследствие выраженной крупнопористости носителя препараты отличаются хрупкостью и пониженным диффузионным сопротивлением и 
могут быть использованы в колоночном режиме. Температурный оптимум иммобилизованных ХТ и БПА равен $50^{\circ}$, что выше оптимума свободных ферментов. pН-оптимум иммобилизованной БПА равен 8,0 и смещен в щелочную сторону по сравнению с рН-оптимумом свободного фермента, у которого он равен 7,5. pН-оптимум ХТ по сравнению с рНоптимумом свободного фермента смещен в щелочную сторону на одну единицу и равен 9,0.

Иммобилизованные ферменты стабильны при хранении их во влажном состоянии при температуре $4-6^{\circ}$ в $0,001 \mathrm{M} \mathrm{HCl}$. Препарат иммобилизованного ХT после пятимесячного хранения сохранил $64 \%$ первоначальной активности.

\title{
ЛИ Т Е Р А Т У Р А
}

1. Orth, H. D., B r ümmer, H., Angew. Chem., 84, 319 (1972).

2. Grysz ki ew i c h, J., Folia biol., 49, 119 (1971).

3. Кё ст н ер А. И., Креэн М. И., Производство и применение иммобилизованных ферментов. Обзорная информация ЭстНИИ научно-технич. информ. и техн.экон. иссл., Таллин, 1973.

4. Органические синтезы, 3, М., 1954, с. 3.

5. Beilste in, S., Handbuch der Organischen Chemie, Bd. II, 1929, S. 278.

6. We et a 11, H. H., Hers h, L. S., Biochim. Biophys. Acta, 185, 464 (1969).

Ннститут химии

Академии наук Эстонской ССР
Поступила в редакцию 18/XII 1975

\author{
EESTI NSV TEADUSTE AKADEEMIA TOIMETISED 26. KOIDE \\ KEEMIA * GEOLOOGIA 1977, Nr. 4 \\ ИЗВЕСТИЯ АКАДЕМИИ НАУК ЭСТОНСКОП ССР. ТОМ 26 \\ ХИМИЯ * ГЕОЛОГИЯ. 1977, № 4
}

Ю. КАУП, К. ТАЮР, О. ЭИЗЕН

\section{ВЛИЯНИЕ МОЩНОСТИ РАЗРЯДА НА ПРЕВРАЩЕНИЕ Н-ПЕНТАНА В ПЛАЗМЕ ВЧ-ТЛЕЮЩЕГО РАЗРЯДА}

J. KAUP, K. TAJUR, O. EISEN. HUUMLAHENDUSE VOIMSUSE MOJUST $n$-PENTAANI MUUNDU. MISELE

J. KAUP, K. TAJUR, O. EISEN. INVESTIGATION OF THE DEPENDENCE OF THE POWER LEVEL OF GLOW DISCHARGE ON THE DECOMPOSITION OF $n$-PENTANE

В работе [1] нами показано, что в плазме тлеющего разряда из $H$-пентана образуются газовые, жидкие и твердые углеводороды.

Так как плотность электронов в разряде зависит от мощности его [ [2], можно предположить, что последняя может оказывать существенное влияние как на состав продуктов, так и на степень превращения углеводородов в тлеющем разряде. Этого мнения придерживаются и авторы [3].

Нами изучено влияние мощности разряда на процесс превращения $\boldsymbol{H}$-пентана в плазме ВЧ-тлеющего разряда. Использовали аппаратуру, аналогичную описанной в работе [']. Газами-носителями служили водо- 